\title{
Integrin alpha 4 / beta 1 (CD49d/CD29) is a component of the murine IgG3 receptor
}

Carolyn Saylor Hawk ${ }^{\dagger}$, Carolina Coelho ${ }^{+}$, Diane Sthefany Lima de Oliveira, Verenice Paredes, Patrícia

Albuquerque, Anamélia Lorenzetti Bocca, Ananésia Correa dos Santos, Victoria Rusakova, Heather

Holemon, Maria Sueli Soares Felipe, Hideo Yagita, André Moraes Nicola ${ }^{* \ddagger}$, Arturo Casadevall ${ }^{\S \ddagger}$

${ }^{\dagger}$ These authors have contributed equally and share first authorship.

${ }^{\ddagger}$ These authors have contributed equally and share senior authorship.

Department of Molecular Microbiology \& Immunology, Johns Hopkins Bloomberg School of Public

Health. Baltimore, MD 21205, USA.

Faculty of Medicine, University of Brasília. Brasília, DF 70910-900, Brazil.

Institute of Biological Sciences, University of Brasília. Brasília, DF 70910-900, Brazil.

Sigma-Aldrich Co., St. Louis, MO 63103, USA.

Department of Immunology, Juntendo University School of Medicine, Tokyo, Japan.

Graduate Program in Genomic Sciences and Biotechnology, Catholic University of Brasília. Brasília, DF

70790-160, Brazil.

Faculty of Ceilândia, University of Brasília. Brasília, DF 72220-275, Brazil.

Karan Technologies Research and Development. Brasília, DF 70632-200, Brazil.

\section{Contact Information}

${ }^{\S}$ Arturo Casadevall

615 N. Wolfe Street

Room E5132

Baltimore, Maryland 21205

+1-410-955-3457

+1-410-955-0105

acasadevall@jhu.edu
*André Moraes Nicola

Campus Universitario Darcy Ribeiro

Faculdade de Medicina, sala BC-103

Brasília-DF, Brazil. 70910-900

+55-61-98581-0129

andre.nicola@gmail.com 


\section{Summary}

Antibodies exert several of their effector functions by binding to cell surface receptors. For murine IgG3 (mlgG3) the identity of its receptors (and the very existence of a receptor) is still under debate, as not all mlgG3 functions can be explained by interaction with Fcy-receptor I (FcyRI). This implies the existence of an alternate receptor, whose identity we sought to pinpoint. We found that blockage of the alpha4/beta1 integrin (Itga4/Itgb1) selectively hampered binding of mlgG3 to macrophages and mlgG3mediated phagocytosis. Manganese, an integrin activator, increased mlgG3 binding to macrophages. Blockage of FcyRl or Itgb1 inhibited binding of different mlgG3 antibodies to variable extents. Our results indicate an integrin component in the $\mathrm{mlgG3}$ receptor. Given the more ancient origin of integrins in comparison with $\mathrm{F} c \gamma \mathrm{R}$, this observation could have far ranging implications for our understanding of the evolution of antibody-mediated immunity, as well as in immunity to microorganisms, pathogenesis of autoimmune diseases and antibody engineering. 


\section{Introduction}

Antibodies are amongst the most studied biomolecules in history. Starting with late $19^{\text {th }}$ century studies on serum therapy that gave von Behring the first Nobel Prize in Medicine, a steady stream of important discoveries clarified how B-cells make antibodies, their structure and functions in both health and disease. This body of knowledge allowed harnessing of antibodies as biotechnological tools with major applications in diagnosis and therapy of human and animal diseases. Behind their success both as immune effectors and as biotechnological tools is the fact that antibodies are bifunctional molecules, with a variable domain that recognizes the antigen and a constant domain that mediates effector functions. For the $\lg G$ antibodies, the majority of these functions depend upon binding of the antibody Fcy domain to cell-surface Fcy-receptors ( $F c \gamma R$ ), which in turn activate (or inhibit) immune cells and regulate immunity (Casadevall and Pirofski, 2006; Nimmerjahn and Ravetch, 2008). Thus, binding of IgG to $F c \gamma R$ is essential to such varied phenomena as phagocytosis of a pathogen by macrophages, tissue damage resulting from deposited immune complexes and destruction of tumor cells by therapeutic anticancer antibodies.

The detection, cloning and sequencing of most FcyRs date from research in the 1970's and 1980's (Hulett and Hogarth, 1994). The latest discovered receptor, FcyRIV, was found by sequence homology with known FcyR a subunits (Nimmerjahn et al., 2005). The known FcyRs explain functions of murine $\operatorname{lgG1}$, IgG2a and IgG2b. In spite of several decades of research, one major riddle remains in this field. In 1981, Diamond and Yelton posited that murine $\lg G 3$ ( $\mathrm{mlgG3}$ ) had its own receptor based on the observation that a clone of the macrophage-like J774 cell line lost the ability to phagocytose mlgG3opsonized particles while retaining functionality with all other $\mathrm{mlgG}$ isotypes, indicating the existence of a distinct receptor for mlgG3 (Diamond and Yelton, 1981). In the late 1990s, another group reported that murine $F c \gamma R I$, the high-affinity FcyR, was responsible for mlgG3 function, based on the failure of 
FcyRI-deficient murine bone marrow-derived macrophages (BMMs) to internalize mlgG3-coated erythrocytes (Gavin et al., 1998). However, subsequent studies have established that mlgG3 does not have measurable affinity for the classical FcyRs (Bruhns et al., 2009; Nimmerjahn and Ravetch, 2006, 2008). Furthermore, mlgG3 was found to be opsonic even when all the known FcyRs were absent or blocked (Saylor et al., 2010). In other models, mlgG3 antibodies mediated its function solely by activating complement, without evidence of binding to any cell-surface receptor (Azeredo da Silveira et al., 2002; Han et al., 2001; Hjelm et al., 2005). Thus, the receptor whose function was missing in Diamond's 1981 sub-clone of the $J 774$ cell line remains obscure, and the very existence of a mlgG3 receptor is uncertain.

In human cells, all human IgG isotypes unambiguously interact with known FcyRs (Hulett and Hogarth, 1994; Nimmerjahn and Ravetch, 2006, 2008). There is no direct equivalence between murine and human IgG isotypes, but human IgG2 (hlgG2) is related to mlgG3 because both mice and humans have a clear bias towards responding to carbohydrate antigens with these isotypes (Perlmutter et al., 1978; Scott et al., 1988; Slack et al., 1980). Additionally, mlgG3 frequently behaves as a cryoglobulin, being involved in autoimmune diseases such as glomerulonephritis or lupus-like skin lesions in mice (Abdelmoula et al., 1989; Kuroda et al., 2005; Otani et al., 2012); hlgG2 association with cryoglobulinemia in humans was never detected. though. Technological interest in the mlgG3 isotype is marginal because mlgG3 monoclonal antibodies are prone to aggregation as a result of inter-molecular constant region interactions (Greenspan and Cooper, 1992), which decreases productivity, stability and safety. However, engineering antibodies to modify their binding to different FcyRs and thus modulate pharmacological effects is an important strategy in monoclonal antibody drug development (Saxena and $\mathrm{Wu}, 2016)$. The existence and identity of this yet unknown non-FcyR IgG receptor could thus be relevant in Immunology, Immunopathology and production of therapeutic antibodies. 
Here we show the results of a loss-of-function screening with shRNAs to 15,000 murine genes indicating that integrin beta 1 (Itgb1) and integrin alpha 4 (Itga4) form a cell-surface receptor for $\mathrm{mlgG3}$ in mouse macrophages. We provide experimental validation of this finding via loss and gain of function assays for several mlgG3 antibodies. The finding of a non-FcyR receptor for IgG antibodies could have large impact on our understanding of the humoral immune response and on antibody engineering.

\section{Results}

\section{Screening for the IgG3 receptor using pooled shRNA libraries}

We designed and conducted a screen for the mlgG3 receptor in mice with a pooled shRNA library from the RNAi Consortium (Moffat et al., 2006). Using engineered lentiviral vectors targeting 15,000 different mouse genes we transduced $\mathbf{J 7 7 4}$ cells to generate a pool of macrophage-like cells, each with a single gene knocked down. We screened the knock-down library by sorting twice for cells that showed decreased binding to mlgG3 but had normal levels of mlgG1 binding (Figure 1A-B). Sequencing the shRNA sequences of pre-sort and post-sort $\mathrm{J774}$ pools determined that 8,145 of the 8,937 shRNA sequences detected were differentially represented in the separated populations. Of these, 2,794 had higher representation in the post-sort population, i.e. low binding to mlgG3. We narrowed our search to select for plasma membrane proteins, which were targeted by 266 of these shRNAs. Among these 266, we chose five candidate genes, based on known macrophage expression and possible role in phagocytosis or Ab binding: Lrig2 (leucine-rich repeats and immunoglobulin-like domains 2), Itgb2I (Integrin beta 2-like, or Pactolus), Itgb1 (Integrin beta 1), TIr2 (toll-like receptor 2), and Fasl (Fas ligand).

To confirm their involvement in mlgG3 binding, we transduced individual shRNA sequences targeting these candidates ( 5 each for Lrig2, Itgb2I and Itgb1, 2 for Fasl and 1 for TIr2) into J774 cells. We then performed phagocytosis assays to detect decreased uptake of $C$. neoformans after opsonization with 3E5-IgG3, a hybridoma-derived monoclonal antibody that binds to the fungal capsule (Yuan et al., 1995). 
The experiment was performed in the presence of 2.4G2 antibody (Fc block) - which blocks CD16 and CD32, the alpha subunits of FcyRIII and FcyRII. We also used antibodies to CD18, CD11b and CD11c (CR block) to inhibit complement receptors CR3 and CR4, which can directly bind to $C$. neoformans capsule carbohydrate upon antibody binding to the capsule and promote complement independent phagocytosis (Taborda and Casadevall, 2002). Although all candidates showed uptake of mlgG3-C. neoformans, two clones transduced with Itgb1 shRNAs showed lower (albeit not statistically significant) phagocytic efficacy (Figure 1C). These two clones, Itgb1 c. and e., were also the ones that showed the greatest reduction in surface expression of Itgb1 (Figure S1).

\section{mlgG3 binding to macrophages depends on Itgb1 expression and divalent \\ cations}

Given the encouraging screening hit, we tested the effect of integrins on binding of fluorescently labeled $\mathrm{mlgG3}$ and $\mathrm{mlgG1}$ antibodies to macrophages. First we took advantage of the fact that integrin activity is modulated by divalent cations (Leitinger et al., 2000) to test antibody binding to macrophages in the presence or absence of $\mathrm{Mg}^{2+}, \mathrm{Mn}^{2+}$ and $\mathrm{Ca}^{2+}$. Consistent with an integrin type of interaction, $1 \mathrm{mM} \mathrm{Mn}^{2+}$ increased the binding of $\mathrm{mlgG} 3$ to $\mathrm{J774}$ cells. In the presence of $1 \mathrm{mM} \mathrm{Ca}^{2+}$ and of $1 \mathrm{mM} \mathrm{Mg}^{2+} \mathrm{mlgG}$ binding was increased and unchanged, respectively (Figure 2A). We next tested a range of concentrations of each cation, which showed that the increased mlgG3 binding resulting from supplementation with divalent cations was dose-dependent and that the divalent cations had little effect on mlgG1 binding to cells (Figure S2). Finally, when these cations were combined, the increased mlgG3 binding in the presence of $\mathrm{Mn}^{2+}$ and $\mathrm{Ca}^{2+}$ was additive, whereas addition of $\mathrm{Mg}^{2+}$ had little effect on $\mathrm{Ca}^{2+}$ but dampened the effect of $\mathrm{Mn}^{2+}$ (Figure S3).

Next we evaluated the binding of IgG3 to $\mathrm{J774}$ cells under Itgb1 interference by shRNA and/or HMß1-1, a hamster mAb that inhibits murine Itgb1. To increase the efficiency of $\operatorname{ltg} b 1$ knockdown, we sorted the 
population of $\mathrm{J774}$ cells transduced with Itgb1 c. and e. and selected for cells with lowest expression of Itgb1. With integrins activated by $\mathrm{Mn}^{2+}$ and $\mathrm{Ca}^{2+}$, Itgb1 knockdown slightly decreased $\mathrm{mlgG} 3$ binding in comparison with control cells (Figure $2 \mathrm{~B}-\mathrm{C}$ ). In the presence of $\mathrm{HM} \beta 1-1$ all three cell lines manifested decreased binding of IgG3 (Figure 2D). When the effects of the shRNAs and HMß1-1 were combined in the presence of divalent cations, the median IgG3 fluorescence decreased by roughly $50 \%$.

To confirm the results obtained with macrophage-like J774 cells, we used primary macrophages. Since Itgb1 is essential in many cellular functions, genetically deficient (knock-out) mice are not viable. To overcome this, we used BMM from LysM-Cre, Itgb $1^{\text {flox/flox }}\left(\operatorname{Itgb} 1^{--}\right)$mice, in which Itgb1 is conditionally knocked out in macrophages and other myeloid cells. Flow cytometry with PE-labeled HMß1-1 showed Itgb1 deletion in about 50\% of the BMM Itgb1 ${ }^{-1}$ mice, in comparison with a 95\% Itgb1-positive population derived from the Cre-negative, $\operatorname{Igb} 1^{\text {flox/flox }}\left(\operatorname{Itgb} 1^{f / f}\right)$ control littermate mice (Figure 2E). Flow cytometric mlgG3 binding assays showed that like J774 cells, BMM bound monomeric mlgG3 and that binding was increased in presence of $\mathrm{Ca}^{2+}$ and $\mathrm{Mn}^{2+}$. However, binding of $\mathrm{Ab}$ to the cells was similar between Itgb1 $1^{-/}$and Itgb1 $1^{\mathrm{f} / \mathrm{f}}$ cells (Figure 2F). Since BMM had been used by Gavin and colleagues (Gavin et al., 1998) to conclude that $\mathrm{F} c \gamma \mathrm{Rl}$ is an $\mathrm{mlgG3}$ receptor, we repeated the $\mathrm{mlgG3}$ binding in presence of excess monomeric mlgG2a, which binds to FcyRI with high affinity (Nimmerjahn and Ravetch, 2008). This resulted in no clear difference between the $\operatorname{ltgb} 1^{-}$and $\operatorname{ltgb} 1^{\mathrm{f} / \mathrm{f}}$ cells in $\mathrm{mlgG} 3$ binding to $\mathrm{BMM}$ (Figure $2 \mathrm{G})$.

\section{Loss of Itgb1 function decreases mlgG3-mediated phagocytosis}

Next we studied the role of Itgb1 in mlgG3-mediated phagocytosis. We repeated the phagocytosis assay with the sorted Itgb1 c. and Itgb1 e. knock-downs as well as cells transduced with a control shRNA; we also further interfered with Itgb1 function using HMB1-1. As shown in Figure 3A, shRNA-mediated knockdown and HMß1-1 blockage affected phagocytosis mediated by 3E5-mlgG3; in addition to 
decreasing the percent phagocytosis, Itgb1 shRNA and HMß1-1 resulted in a significant decrease in the number of $C$. neoformans cells internalized per macrophage (Figure 3B). Remarkably, we observed almost complete abrogation of $C$. neoformans phagocytosis mediated by 3E5-mlgG3 when both Itgb1 blocking strategies were combined.

To confirm the results obtained with macrophage-like J774 cells, we used primary macrophages. BMM from both $\operatorname{lgb} 1^{\mathrm{t} / \mathrm{f}}$ and the $\operatorname{ltg} b 1^{-/-}$mice showed high levels of phagocytosis of $C$. neoformans cells coated with both 3E5-mlgG1 and 3E5-mlgG3. We had previously shown that BMM phagocytosis of 3E5mlgG3-coated C. neoformans was not affected by Fc block and was only partially reduced by CR block, an indication of the existence of a non-Fcy receptor (Saylor et al., 2010). In the present experiments, BMM from $\operatorname{ltg} b 1^{-/-}$mice phagocytosed $C$. neoformans to the same extent as those from control $\lg b 1^{\mathrm{f} / \mathrm{f}}$ mice, presumably because of the redundancy between Itgb1 and complement receptors (Figure $3 \mathrm{C}$ ). In presence of CR block, however, 3E5-mlgG3-mediated phagocytosis was drastically reduced in $/ \operatorname{tg} 61^{-/}$ cells in comparison with control /tgb $1^{\mathrm{f} / \mathrm{f}} \mathrm{BMM}$; integrin knockout had very little effect on 3E5-mlgG1 opsonization.

To test how generalizable these findings are, we used genetic engineering to produce two pairs of recombinant mlgG1 and mlgG3 antibodies. For the first pair, 2H1-mlgG1 and 2H1-mlgG3, we have used the variable region sequences of another antibody to $C$. neoformans capsule whose Fab structure has been solved by X-ray crystallography (Young et al., 1997). The other pair, 4-4-20-mlgG1 and 4-4-20$\mathrm{mlgG3}$, has the variable domains of a high affinity antibody to the hapten fluorescein isothiocyanate (FITC). Detailed structural information is also available for the 4-4-20 Fab structure (Whitlow et al., 1995). Recombinant antibodies were produced by co-transfecting mammalian cells with vectors expressing $2 \mathrm{H} 1$ and 4-4-20 heavy and light chains. Comparing the phagocytosis assays performed with $C$. neoformans cells coated with $3 \mathrm{E} 5$ hybridoma antibodies with the ones performed with $2 \mathrm{H} 1$ antibodies, we have observed the same pattern of almost complete abrogation of mlgG1-mediated phagocytosis 
upon $\mathrm{CR}$ and Fc block (Figure 3D). However, 2.4G2 did significantly reduce the phagocytosis of $C$. neoformans coated with $2 \mathrm{H} 1$-mlgG3 from $38 \%$ to $16 \%$ ( $p<0.0001)$ when compared to mlgG3-coated $C$. neoformans in presence of CR block. This already low figure was further reduced to $8.4 \%$ upon addition of $H M \beta 1-1(p<0.0001)$.

With the 4-4-20 antibody pair, we made phagocytosis assay using a different particle, FITClabeled sheep red blood cells (SRBC). The background in this experiment was higher than that in experiments with C. neoformans, as we observed $8.7 \%$ phagocytosis with non-opsonized FITC-labeled SRBCS (Figure 3E). Addition of 2.4G2 reduced 4-4-20-IgG1 phagocytosis to the same level observed with non-opsonized sRBC. It also reduced 4-4-20-IgG3 phagocytosis, but to a level (19\%) that was still significantly above background $(p<0.0001)$. HMß1-1 alone had no effect on the phagocytosis rates. When 2.4G2 and HMß1-1 were combined, the phagocytosis rate was decreased to $8.4 \%(p=0.0087)$. The results from all phagocytosis experiments are summarized in Figure 3F.

\section{Integrin alpha 4 pairs with Itgb1 to mediate mlgG3 function}

Integrins are heterodimeric complexes, composed of beta and alpha subunits. Using shRNAs to decrease surface expression of five alpha integrins that can pair with $\operatorname{ltg} 11$ and are known to be expressed in macrophages (Itga3, Itga4, Itga5, Itga9 and Itgav), we tested which ones decreased phagocytosis of mlgG3-coated C. neoformans. As shown in Figure 4, two shRNAs targeting Itga4 reduced 3E5-mlgG3 phagocytosis about two-fold, whereas the knockdown of any of the other alpha subunits had no effect on fungal internalization. We note that both Itgb1 and Itga4 knockdown had significant effects in cell health, an unavoidable confounding factor. However, we did detect loss of 3E5-mlgG3-mediated phagocytosis without loss of mlgG1 function for one of the shRNA clones targeting Itga4. Therefore, mlgG3 phagocytosis is dependent on Itgb1 and Itga4 surface expression, presumably due to integrin heterodimer formation. 


\section{Gain-of-function assays with Itgb1}

We transfected Chinese Hamster Ovary ( $\mathrm{CHO}$ ) cells so they would express murine Itgb1 to perform gainof-function assays. In absence of divalent cations, binding of 3E5-mlgG3 but not 3E5-mlgG1 increased when comparing $\mathrm{CHO}-\mathrm{Itg} b 1$ cells with untransfected controls (Figure 5A). Similar to $\mathrm{J774}$ cells, $\mathrm{Ca}^{2+}$ and $\mathrm{Mn}^{2+}$ increased 3E5-mlgG3 binding to $\mathrm{CHO}$ cells and murine Itgb1 overexpression increased the proportion of 3E5-mlgG3-positive $\mathrm{CHO}$ cells from $75 \%$ to $97 \%$. This increase in binding was almost completely abrogated by addition of $\mathrm{HM} \beta 1-1$, which does not bind to or inhibit native hamster integrin beta 1 on $\mathrm{CHO}$ cells (Figure 5B).

\section{A new model for mlgG3-receptor interactions}

Almost four decades ago Diamond and Yelton proposed the existence of another antibody receptor. Since that time, several research groups have delved into the issue of the mlgG3 receptor. Three different hypotheses surfaced from these studies:

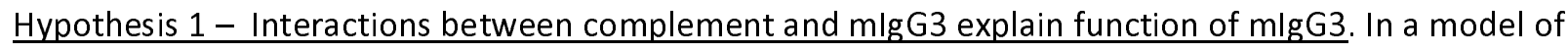
anemia induced in mice by injection of high affinity anti-RBC antibodies, Fcy knockout reduced mlgG2a-, mlgG2b- and mlgG1-induced but had no effect on mlgG3-induced anemia. However, the mlgG3 anemia was abrogated in C3-deficient animals, suggesting that it functions simply by activating complement (Azeredo da Silveira et al., 2002). A monoclonal mlgG3 to Candida albicans was also only protective when complement C3 was available (Han et al., 2001). Hjelm and colleagues also found that mlgG3 enhancement of the antibody response was normal in FcyRI-deficient mice, but that this enhancement was abolished in the absence of complement (Hjelm et al., 2005). Earlier, Stahl et al had also found that knocking out Fcy receptors made no difference in mlgG3 enhancement and that $\mathrm{C} 3$ was important for IgG3-mediated antibody enhancement; however, they were not able to completely abrogate the 
enhancement and found lower but non-negligible enhancement with mlgG3 in animals depleted from C3 with cobra venom or in CR2 knockout mice (Diaz de Stahl et al., 2003).

Hypothesis 2 - FcyRl is the $\mathrm{mlgG3}$ receptor. Experiments made with macrophages from transgenic mice showed that FcyRI knockout abolished mlgG3-mediated phagocytosis of erythrocytes.(Gavin et al., 1998). This hypothesis can be further supported by earlier studies with murine monoclonal antibodies to human $\mathrm{CD} 3$, which showed that human monocytes bound mlgG3 via the high affinity FcyRI (Ceuppens and Van Vaeck, 1989; Parren et al., 1992).

Hypothesis 3 - There is an unknown dedicated receptor for mlgG3. In a murine model of malaria, an mlgG3 monoclonal antibody remained protective in animals lacking the common Fcy chain (Rotman et al., 1998) and the FcyRI alpha chain (Vukovic et al., 2000). Our group has shown evidence of functional differences between a monoclonal mlgG3 and its isotype switches in a murine model of acute lethal toxicity (Lendvai et al., 2000). Moreover, we have observed mlgG3-mediated phagocytosis in macrophages derived from animals lacking several genes encoding $\mathrm{Fc} Y$ and complement receptor subunits (Saylor et al., 2010).

These three hypotheses appear at first glance to be mutually exclusive: the experiments leading to conclusion (1) contradict (2) and (3); in some reports mlgG3 mediated function even when complement was absent or complement receptors blocked, contradicting (1); in others, blocking or knocking out FcyRs had no effect in mlgG3 functions, contradicting (2). However, our results suggest a model that can reconcile all three hypotheses (Figure 6). We propose that integrins play a part in mlgG3 binding and phagocytosis, as do FcyRs and complement. In some of our experiments, (e.g. Figure 3A), Itgb1 blockage drastically reduced but did not abolish mlgG3 function whereas FcyRII/III blockage had no effect; the same antibody batch was used for the flow cytometry binding assay shown in Figure 2G, which shows excess soluble mlgG2a (a competitive FcpRI block) partially decreasing mlgG3 binding. Other antibody 
batches, such as the recombinant $2 \mathrm{H} 1$ antibodies used in the phagocytosis assay shown in Figure 3D, do show a similar pattern of mlgG3-mediated phagocytosis reduction upon Itgb1 blockage; the extent of the reduction, however, is not as large as what we observed with 3E5-mlgG3. Moreover, FcyRII/III blockage did affect 2H1-mlgG3-mediated phagocytosis, whereas it did not affect 3E5-mlgG3. Adding up observations of different mlgG3 batches mediating phagocytosis by integrin and FcyR to different extents, the partial competition with monomeric mlgG2a and the fact that in none of the experiments integrin blockage completely abolished mlgG3 function or binding suggests that monoclonal mlgG3 preparations are actually a mixture of isoforms binding to $\mathrm{Fc} \gamma \mathrm{Rs}$ and to Itgb1. The existence of a mixture of isoforms that varies in each batch could explain the seemingly disparate data on whether FcyRI or an unknown protein is the $\mathrm{mlgG3}$ cell surface receptor. Such heterogeneity is very common and has been extensively studied in industrial monoclonal antibody production settings, in which variations in glycosylation have significant impact on biologic drug pharmacokinetics and pharmacodynamics (Liu, 2015).

\section{Discussion}

Antibody isotype switching in response to antigens of different compositions or origins is conserved in many animals, probably because different antibody isotypes have different effector functions and thus allow a host to tailor the immune response to each particular threat. Antibody engineers also change the isotype of the antibodies they work with to obtain biotechnological or pharmaceutical tools with different effector functions. In both cases, most of the functional differences between isotypes can be ascribed to their differential interactions with cell surface receptors.

Integrins are transmembrane receptors present as $\alpha+\beta$ heterodimers that regulate cell- cell and cellmatrix interactions (Cabodi et al., 2010). Several integrins also have an intrinsic ability to mediate phagocytosis as well (Dupuy and Caron, 2008). Probably the most studied ones are the $\beta 2$ integrin 
phagocytic complement receptors $C R 3(\alpha M+\beta 2)$ and $C R 4(\alpha X+\beta 2)$. In the $C$. neoformans system, Itgb2 was shown to mediate complement-independent phagocytosis as a result of direct interactions with the capsular polysaccharide component of antibody-coated cryptococcal cells (Taborda and Casadevall, 2002). $\beta 1$ integrins can also mediate particle internalization: (1) macrophages lacking Itgb1 expression manifest reduced phagocytic capacity for some types of bacteria (Wang et al., 2008); (2) microglia are able to phagocytose fibrillar beta-amyloid in vitro in a mechanism that does not utilize FcyRs or CRs and is blocked by an antagonist to Itgb1 (Koenigsknecht and Landreth, 2004); and (3) Itgb1 pairs with $\alpha 2$ integrin to form a receptor that binds complement component C1q (Zutter and Edelson, 2007). The interaction between IgG molecules and non-FcyR cell surface proteins has also been reported before (Anthony et al., 2011).

Additional evidence for the conclusion that Itgb1 is involved in mlgG3 function comes from experiments using divalent cations. Integrins have many binding sites for these ions, each with distinct functional roles (Zhang and Chen, 2012). For most integrins, $\mathrm{Mn}^{2+}$ binding to one of these motifs (the metal iondependent adhesion site - MIDAS) changes the integrin conformation into an active open state. Consistent with this, $\mathrm{Mn}^{2+}$ increased binding of $\operatorname{lgG} 3$ to surface of cells. $\mathrm{Mg}^{2+}$, which also binds to MIDAS to activate integrins, resulted in more $\mathrm{mlgG3}$ bound to $\mathrm{J774}$ cells; however, the activation mediated by $\mathrm{Mg}^{2+}$ seemed to be different from the $\mathrm{Mn}^{2+}$ activation, as addition of $\mathrm{Mg}^{2+}$ competed with $\mathrm{Mn}^{2+}$ and completely abolished increased $\mathrm{mlgG} 3$ binding. In addition to the $\mathrm{Mn}^{2+} / \mathrm{Mg}^{2+} \mathrm{MIDAS}$, integrins have different types of $\mathrm{Ca}^{2+}$ binding sites (Leitinger et al., 2000). One of them, with mM affinity, flanks MIDAS and, when occupied, inhibits $\mathrm{Mg}^{2+} / \mathrm{Mn}^{2+}$ binding and thus integrin function. However, $\mathrm{Ca}^{2+}$ actually increased mlgG3 surface binding in our assays. This seemingly surprising result is actually very informative, as a detailed study on the effect of calcium in $\beta 1$ integrins showed it decreased the activation of the heterodimers containing $\alpha 2, \alpha 3, \alpha 5$ and $\alpha 6$ but increased the activation of the $\alpha 4 / \beta 1$ integrin (Bazzoni et al., 1998), an indication that Itga4 is the Itgb1 partner in the mlgG3 receptor. 
Given that the problem of the mlgG3 receptor identity has vexed investigators and lingered unsolved for decades, we arrive at our conclusions humbly. The most straightforward interpretation of our findings is that Itga4/Itgb1 is at least part of an mlgG3 receptor complex. We acknowledge that we lack direct evidence for an immunoglobulin-integrin protein-protein interaction, which in combination with the functional data from our study would provide unequivocal evidence for an mlgG3 integrin receptor. Nevertheless, the available data provide strong evidence associating integrin function with IgG3 phagocytosis, which leads to a tantalizing suggestion regarding the evolution of the humoral response. Antibodies appeared around half a billion years ago, with cartilaginous fishes. The Fcy receptors, however, are much more recent: they first appeared with mammals. The most accepted interpretation is that through most of its existence, antibodies functioned solely by activating complement and neutralizing antigens. However, as integrins are far more ancient and are present in all metazoans, they could actually have functioned as early IgG receptors for non-mammalian vertebrates. In this regard, it is interesting to note that $\mathrm{mlgG} 3$ is the murine $\operatorname{lgG}$ isotype whose sequence differs the most from the others and which seems to have appeared first in the evolutionary history of the mouse constant gamma locus (Hayashida et al., 1984). 


\section{Acknowledgements}

We would like to acknowledge Dr. Jinghang Zhang from the Albert Einstein College of Medicine flow

cytometry core facility for technical assistance. AC is supported by National Institutes of Health Grants 5R01A1033774, 5R37AI033142, and 5T32A107506, and CTSA Grants 1 ULI TR001073-01, 1 TLI 1

TR001072-01, and 1 KL2 TR001071 from the National Center for Advancing Translational Sciences.

Facilities were supported by the Center for AIDS research at Albert Einstein College of Medicine; CC was

partially supported by PhD grant SFRH / BD / 33471 / 2008 by Fundação Ciência e Tecnologia; CS was

supported by NIH grant T32 AI07506; AN was partially supported by a Reuni scholarship (MEC-Brasil)

and is currently supported by grants from the Brazilian funding agencies CNPq, FAP-DF and Capes. 


\section{References}

Abdelmoula, M., Spertini, F., Shibata, T., Gyotoku, Y., Luzuy, S., Lambert, P.H., and Izui, S. (1989). IgG3 is the major source of cryoglobulins in mice. J Immunol 143, 526-532.

Anthony, R.M., Kobayashi, T., Wermeling, F., and Ravetch, J.V. (2011). Intravenous Gamma Globulin Suppresses Inflammation through a Novel Th2 Pathway. Nature In press.

Audic, S., and Claverie, J.M. (1997). The significance of digital gene expression profiles. Genome Res 7, 986-995.

Azeredo da Silveira, S., Kikuchi, S., Fossati-Jimack, L., Moll, T., Saito, T., Verbeek, J.S., Botto, M., Walport, M.J., Carroll, M., and Izui, S. (2002). Complement activation selectively potentiates the pathogenicity of the IgG2b and IgG3 isotypes of a high affinity anti-erythrocyte autoantibody. J Exp Med 195, 665-672.

Bazzoni, G., Ma, L., Blue, M.L., and Hemler, M.E. (1998). Divalent cations and ligands induce conformational changes that are highly divergent among beta1 integrins. J Biol Chem 273, 6670-6678. Bruhns, P. (2012). Properties of mouse and human IgG receptors and their contribution to disease models. Blood 119, 5640-5649.

Bruhns, P., Iannascoli, B., England, P., Mancardi, D.A., Fernandez, N., Jorieux, S., and Daeron, M. (2009). Specificity and affinity of human Fcgamma receptors and their polymorphic variants for human IgG subclasses. Blood 113, 3716-3725.

Cabodi, S., Di Stefano, P., Leal Mdel, P., Tinnirello, A., Bisaro, B., Morello, V., Damiano, L., Aramu, S., Repetto, D., Tornillo, G., et al. (2010). Integrins and signal transduction. Adv Exp Med Biol 674, 43-54. Casadevall, A., and Pirofski, L.A. (2006). A reappraisal of humoral immunity based on mechanisms of antibody-mediated protection against intracellular pathogens. Adv Immunol 91, 1-44.

Ceuppens, J.L., and Van Vaeck, F. (1989). Human T cell activation induced by a monoclonal mouse IgG3 anti-CD3 antibody (RIV9) requires binding of the Fc part of the antibody to the monocytic 72-kDa highaffinity Fc receptor (FcRI). Cell Immunol 118, 136-146. 
Clausen, B.E., Burkhardt, C., Reith, W., Renkawitz, R., and Forster, I. (1999). Conditional gene targeting in macrophages and granulocytes using LysMcre mice. Transgenic Res 8, 265-277.

Coelho, C., Tesfa, L., Zhang, J., Rivera, J., Goncalves, T., and Casadevall, A. (2012). Analysis of cell cycle and replication of mouse macrophages after in vivo and in vitro Cryptococcus neoformans infection using laser scanning cytometry. Infect Immun 80, 1467-1478.

Diamond, B., and Yelton, D.E. (1981). A new Fc receptor on mouse macrophages binding IgG3. J Exp Med $153,514-519$.

Diaz de Stahl, T., Dahlstrom, J., Carroll, M.C., and Heyman, B. (2003). A role for complement in feedback enhancement of antibody responses by IgG3. J Exp Med 197, 1183-1190.

Dupuy, A.G., and Caron, E. (2008). Integrin-dependent phagocytosis: spreading from microadhesion to new concepts. J Cell Sci 121, 1773-1783.

Fassler, R., Pfaff, M., Murphy, J., Noegel, A.A., Johansson, S., Timpl, R., and Albrecht, R. (1995). Lack of beta 1 integrin gene in embryonic stem cells affects morphology, adhesion, and migration but not integration into the inner cell mass of blastocysts. J Cell Biol 128, 979-988.

Gavin, A.L., Barnes, N., Dijstelbloem, H.M., and Hogarth, P.M. (1998). Identification of the mouse IgG3 receptor: implications for antibody effector function at the interface between innate and adaptive immunity. J Immunol 160, 20-23.

Greenspan, N.S., and Cooper, L.J. (1992). Intermolecular cooperativity: a clue to why mice have IgG3? Immunol Today 13, 164-168.

Han, Y., Kozel, T.R., Zhang, M.X., MacGill, R.S., Carroll, M.C., and Cutler, J.E. (2001). Complement is essential for protection by an IgM and an IgG3 monoclonal antibody against experimental, hematogenously disseminated candidiasis. J Immunol 167, 1550-1557.

Hayashida, H., Miyata, T., Yamawaki-Kataoka, Y., Honjo, T., Wels, J., and Blattner, F. (1984). Concerted evolution of the mouse immunoglobulin gamma chain genes. EMBO J 3, 2047-2053. 
Hjelm, F., Carlsson, F., Verbeek, S., and Heyman, B. (2005). IgG3-mediated enhancement of the antibody response is normal in Fc gammaRI-deficient mice. Scand J Immunol 62, 453-461.

Hulett, M.D., and Hogarth, P.M. (1994). Molecular basis of Fc receptor function. Adv Immunol 57, 1-127. Koenigsknecht, J., and Landreth, G. (2004). Microglial phagocytosis of fibrillar beta-amyloid through a beta1 integrin-dependent mechanism. J Neurosci 24, 9838-9846.

Kuroda, Y., Kuroki, A., Kikuchi, S., Funase, T., Nakata, M., and Izui, S. (2005). A critical role for sialylation in cryoglobulin activity of murine IgG3 monoclonal antibodies. J Immunol 175, 1056-1061.

Leitinger, B., McDowall, A., Stanley, P., and Hogg, N. (2000). The regulation of integrin function by Ca(2+). Biochim Biophys Acta 1498, 91-98.

Lendvai, N., Qu, X.W., Hsueh, W., and Casadevall, A. (2000). Mechanism for the isotype dependence of antibody-mediated toxicity in Cryptococcus neoformans-infected mice. J Immunol 164, 4367-4374.

Liu, L. (2015). Antibody glycosylation and its impact on the pharmacokinetics and pharmacodynamics of monoclonal antibodies and Fc-fusion proteins. J Pharm Sci 104, 1866-1884.

Luo, B., Cheung, H.W., Subramanian, A., Sharifnia, T., Okamoto, M., Yang, X., Hinkle, G., Boehm, J.S., Beroukhim, R., Weir, B.A., et al. (2008). Highly parallel identification of essential genes in cancer cells. Proc Natl Acad Sci U S A 105, 20380-20385.

Moffat, J., Grueneberg, D.A., Yang, X., Kim, S.Y., Kloepfer, A.M., Hinkle, G., Piqani, B., Eisenhaure, T.M., Luo, B., Grenier, J.K., et al. (2006). A lentiviral RNAi library for human and mouse genes applied to an arrayed viral high-content screen. Cell 124, 1283-1298.

Mukherjee, J., Casadevall, A., and Scharff, M.D. (1993). Molecular characterization of the humoral responses to Cryptococcus neoformans infection and glucuronoxylomannan-tetanus toxoid conjugate immunization. J Exp Med 177, 1105-1116.

Nimmerjahn, F., Bruhns, P., Horiuchi, K., and Ravetch, J.V. (2005). FcgammaRIV: a novel FcR with distinct IgG subclass specificity. Immunity 23, 41-51. 
Nimmerjahn, F., Gordan, S., and Lux, A. (2015). FcgammaR dependent mechanisms of cytotoxic, agonistic, and neutralizing antibody activities. Trends Immunol 36, 325-336.

Nimmerjahn, F., and Ravetch, J.V. (2006). Fcgamma receptors: old friends and new family members. Immunity 24, 19-28.

Nimmerjahn, F., and Ravetch, J.V. (2008). Fcgamma receptors as regulators of immune responses. Nat Rev Immunol 8, 34-47.

Noto, K., Kato, K., Okumura, K., and Yagita, H. (1995). Identification and functional characterization of mouse CD29 with a mAb. Int Immunol 7, 835-842.

Otani, M., Kuroki, A., Kikuchi, S., Kihara, M., Nakata, J., Ito, K., Furukawa, J., Shinohara, Y., and Izui, S. (2012). Sialylation determines the nephritogenicity of IgG3 cryoglobulins. Journal of the American Society of Nephrology : JASN 23, 1869-1878.

Parren, P.W., Warmerdam, P.A., Boeije, L.C., Capel, P.J., van de Winkel, J.G., and Aarden, L.A. (1992). Characterization of IgG FCR-mediated proliferation of human T cells induced by mouse and human antiCD3 monoclonal antibodies. Identification of a functional polymorphism to human IgG2 anti-CD3. J Immunol 148, 695-701.

Perlmutter, R.M., Hansburg, D., Briles, D.E., Nicolotti, R.A., and Davie, J.M. (1978). Subclass restriction of murine anti-carbohydrate antibodies. J Immunol 121, 566-572.

Raghavan, S., Bauer, C., Mundschau, G., Li, Q., and Fuchs, E. (2000). Conditional ablation of beta1 integrin in skin. Severe defects in epidermal proliferation, basement membrane formation, and hair follicle invagination. J Cell Biol 150, 1149-1160.

Romualdi, C., Bortoluzzi, S., D'Alessi, F., and Danieli, G.A. (2003). IDEG6: a web tool for detection of differentially expressed genes in multiple tag sampling experiments. Physiol Genomics 12, 159-162. Root, D.E., Hacohen, N., Hahn, W.C., Lander, E.S., and Sabatini, D.M. (2006). Genome-scale loss-offunction screening with a lentiviral RNAi library. Nat Methods 3, 715-719. 
Rotman, H.L., Daly, T.M., Clynes, R., and Long, C.A. (1998). Fc receptors are not required for antibodymediated protection against lethal malaria challenge in a mouse model. J Immunol 161, 1908-1912.

Saxena, A., and Wu, D. (2016). Advances in Therapeutic Fc Engineering - Modulation of IgG-Associated Effector Functions and Serum Half-life. Frontiers in immunology 7, 580.

Saylor, C.A., Dadachova, E., and Casadevall, A. (2010). Murine IgG1 and lgG3 isotype switch variants promote phagocytosis of Cryptococcus neoformans through different receptors. J Immunol 184, 336343.

Scott, M.G., Shackelford, P.G., Briles, D.E., and Nahm, M.H. (1988). Human IgG subclasses and their relation to carbohydrate antigen immunocompetence. Diagnostic and clinical immunology 5, 241-248. Slack, J., Der-Balian, G.P., Nahm, M., and Davie, J.M. (1980). Subclass restriction of murine antibodies. II. The IgG plaque-forming cell response to thymus-independent type 1 and type 2 antigens in normal mice and mice expressing an X-linked immunodeficiency. J Exp Med 151, 853-862.

Taborda, C.P., and Casadevall, A. (2002). CR3 (CD11b/CD18) and CR4 (CD11c/CD18) are involved in complement-independent antibody-mediated phagocytosis of Cryptococcus neoformans. Immunity 16, 791-802.

Vukovic, P., Hogarth, P.M., Barnes, N., Kaslow, D.C., and Good, M.F. (2000). Immunoglobulin G3 antibodies specific for the 19-kilodalton carboxyl-terminal fragment of Plasmodium yoelii merozoite surface protein 1 transfer protection to mice deficient in Fc-gammaRI receptors. Infect Immun 68, 30193022.

Wang, Q.Q., Li, H., Oliver, T., Glogauer, M., Guo, J., and He, Y.W. (2008). Integrin beta 1 regulates phagosome maturation in macrophages through Rac expression. J Immunol 180, 2419-2428. Whitlow, M., Howard, A.J., Wood, J.F., Voss, E.W., Jr., and Hardman, K.D. (1995). 1.85 A structure of anti-fluorescein 4-4-20 Fab. Protein engineering 8, 749-761. 
Young, A.C., Valadon, P., Casadevall, A., Scharff, M.D., and Sacchettini, J.C. (1997). The three-

dimensional structures of a polysaccharide binding antibody to Cryptococcus neoformans and its complex with a peptide from a phage display library: implications for the identification of peptide mimotopes. J Mol Biol 274, 622-634.

Yuan, R., Casadevall, A., Spira, G., and Scharff, M.D. (1995). Isotype switching from IgG3 to IgG1 converts a nonprotective murine antibody to Cryptococcus neoformans into a protective antibody. J Immunol $154,1810-1816$.

Zhang, K., and Chen, J. (2012). The regulation of integrin function by divalent cations. Cell adhesion \& migration 6, 20-29.

Zutter, M.M., and Edelson, B.T. (2007). The alpha2beta1 integrin: a novel collectin/C1q receptor. Immunobiology 212, 343-353. 


\section{Figure and Table legends}

Figure 1 - High-throughput screening for a mlgG3 receptor

Panels A and B show $\mathrm{J774}$ cells transduced with the entire library and stained with fluorescent mlgG1 and $\mathrm{mlgG3}$, whereas panel $\mathrm{C}$ shows a secondary screen with individual shRNA clones to test some candidates. (A) Untransduced J774 cells stained with mlgG1-APC and/or mlgG3-DTAF. (B) Comparison of untransduced $\mathrm{J774}$ cells and $\mathrm{J774}$ cells transduced with shRNA library, stained with both mIgG1-APC and mlgG3-DTAF. Data from bottom two panels are the same as the top two panels represented differently to better visualize the population of interest (approximated by red circle). (C) Phagocytosis assay using C. neoformans opsonized with 3E5-mlgG3 and $\mathrm{J} 774$ cells transduced with 17 individual shRNA-encoding lentiviruses targeting five candidates from the screening. All cells were pre-incubated with CR block (mAbs specific for CD18, CD11b and CD11c) and Fc block (mAb 2.4G2, specific for FcyRII and FcyRIII) prior to addition of $C$. neoformans. Control cells were transduced with a non-target shRNA. Four fields were analyzed per well, with one well for each condition. Bars indicate percent phagocytosis (number of macrophages containing ingested C. neoformans divided by the total number of macrophages) with $95 \%$ confidence interval.

Figure 2 - Divalent cations and Itgb1 expression affect mlgG3 binding to macrophages

(A) Fluorescently labeled 3E5-mlgG3 was used to measure by flow cytometry binding of mlgG3 to J774 cells in presence of the divalent cation chelator EDTA, the $\mathrm{Ca}^{2+}$-specific chelator EGTA and the cations $\mathrm{Ca}^{2+}, \mathrm{Mg}^{2+}$ and $\mathrm{Mn}^{2+}$. All chelators and salts were present at $1 \mathrm{mM}$ in PBS. (B) Fluorescently labeled 3E5mlgG3 was used to measure by flow cytometry binding of mlgG3 to J774 cells transduced with Itgb1 and control shRNA in presence or absence of HMB1-1. ( $C$ and D) Median intensity fluorescence of some of 
the samples depicted in panel $\mathrm{B}$, showing that in the presence of $1 \mathrm{mM} \mathrm{Ca}^{2+} / \mathrm{Mn}^{2+} \operatorname{tgb} 1$ shRNAmediated knockdown decreases IgG3 binding. (D) Median intensity fluorescence of other samples depicted in panel $\mathrm{B}$ showing that both in the presence or absence of $1 \mathrm{mM} \mathrm{Ca}^{2+} / \mathrm{Mn}^{2+}, \mathrm{HM} \beta 1-1$ decreases mlgG3 binding. (E) Itgb1 expression on $\operatorname{ltg} b 1^{-/}$or $\operatorname{ltg} b 1^{4 / \mathrm{f}} \mathrm{BMM}$, detected by flow cytometry with fluorescently labeled HMß1-1. (F) Binding of fluorescently labeled 3E5-mIgG3 to BMM in the presence of $1 \mathrm{mM} \mathrm{Ca}^{2+} / \mathrm{Mn}^{2+}$. (G) Binding of fluorescently labeled $\mathrm{mlgG} 3$ to $\mathrm{BMM}$ in presence of excess monomeric mlgG2a.

Figure 3 - Itgb1 silencing, knockout or blockage with HMB1-1 decrease phagocytosis in macrophages

(A) Phagocytosis assay using C. neoformans cells opsonized with 3E5-IgG3 and Itgb1 c. and e. transduced J774 cell lines. Macrophages were pre-incubated with antibodies to block FcyRII/III and complement receptors, as indicated, prior to addition of fungi. (B) Images showing representative fields of the phagocytosis assay shown in panel A. Top two panels represent control cells (C-shRNA) and bottom two panels represent the Itgb1 e. transduced cell line, with blocking conditions denoted at top. (C) Phagocytosis assay with BMMs derived from $\lg b 1^{-/}$mice or their littermate $\operatorname{ltgb} 1^{f / f}$ controls in the presence or absence of CR blocking Abs and C. neoformans cells opsonized with 3E5-mIgG3 or 3E5mlgG1. Bars indicate the percent phagocytosis and the $95 \%$ confidence interval. (D) Phagocytosis assay with recombinant $2 \mathrm{H} 1-\mathrm{mlgG} 1$ and $2 \mathrm{H} 1-\mathrm{mlgG} 3$ antibodies and $\mathrm{C}$. neoformans. Bars indicate the percent phagocytosis and the $95 \%$ confidence interval. (E) Phagocytosis of FITC-labeled sRBCs coated with recombinant 4-4-20-mlgG1 and 4-4-20-mlgG3 antibodies. In panels A, C, D and E the p-values were calculated with Fisher's exact test. Bars indicate the percent phagocytosis and the $95 \%$ confidence interval. At least three fields were analyzed per well, with at least two wells per condition. (F) Model summarizing the data obtained with different phagocytosis assays. The black arrows indicate results that 
reproduced what had been previously known about the interaction of $\mathrm{mlgG}$ isotypes and Fcy-receptors (Bruhns, 2012; Nimmerjahn et al., 2015) and between the C. neoformans capsule and CR3 (Taborda and Casadevall, 2002). The red arrows indicate the Itga4/Itgb1 role in mlgG3-mediated phagocytosis demonstrated in the other panels.

Figure 4 - Phagocytosis with $J 774$ cells transduced with shRNAs to integrin alpha chains

J774 cells were transduced with shRNAs targeting five integrin alpha chains which pair with Itgb1 and stably transfected cells selected with puromycin. A phagocytosis assay was then performed with 3E5IgG1 or 3E5-IgG3 antibodies, in the presence of CR block, and fluorescently labeled $C$. neoformans using a scanning cytometer. Bars represent the percent phagocytosis and $95 \%$ confidence interval from one to two independent experiments, each containing three individual wells from which $~ 2,000-18,000$ macrophages were evaluated. All p-values were calculated with Fisher's exact test.

Figure 5 - Expression of Itgb1 in knockout cells confer binding to mlgG3

(A) Fluorescently labeled 3E5-mlgG1 or 3E5-mlgG3 were incubated with untransfected $\mathrm{CHO}$ cells or CHO-Itgb1 cells, which express murine Itgb1. (B) Binding in the presence of $1 \mathrm{mM} \mathrm{Ca}^{2+} / \mathrm{Mn}^{2+}$ and $\mathrm{HMB1-}$ 1.

Figure 6 - Model for mlgG interaction with cell surface receptors Model summarizing the cell surface receptors that mediate $\mathrm{mlgG}$ functions in macrophages. Black arrows indicate known functions, including the direct interaction between $\mathrm{mlgG}$ antibodies and Fcy receptors (Bruhns, 2012; Nimmerjahn et al., 2015) and the indirect interaction with complement 
bioRxiv preprint doi: https://doi.org/10.1101/207274; this version posted October 21,2017 . The copyright holder for this preprint (which was not certified by peer review) is the author/funder, who has granted bioRxiv a license to display the preprint in perpetuity. It is made available under aCC-BY-NC-ND 4.0 International license.

receptor, mediated by classical pathway activation. Red arrows indicate the Itga4/Itgb1 role in mlgG3

function described in this manuscript. 


\section{Materials and Methods}

\section{Mice}

Wild-type C57BI/6 mice (Jackson Laboratories, Bar Harbor, ME), from colonies maintained at the Animal Facility of Albert Einstein College of Medicine, were used to obtain the peritoneal macrophages. To obtain Itgb1-deficient macrophages (Itgb1-/-), a conditional knockout model had to be used because the Itgb1 knockout is lethal. Mice with loxP sites flanking exon 3 of the Itgb1 gene (Raghavan et al., 2000) were crossed with mice expressing the Cre recombinase under control of the lysozyme promoter (Clausen et al., 1999). In all experiments, mice were treated in accordance with institutional guidelines, and the animal protocols were accepted by the institutional review committee of the Albert Einstein College of Medicine, where the experiments were made.

\section{Microbe strains}

Cryptococcus neoformans strains 24067 (serotype D) and H99 (serotype A) were used. The yeast cells were grown overnight in Sabouraud dextrose broth (Difco) at $30^{\circ} \mathrm{C}$ with agitation.

\section{Cell lines}

For experiments the following cell lines were used: J774.16 (J774) - murine macrophage-like cells; L929 murine fibroblast, producer of macrophage colony stimulating factor (M-CSF); CHO-K1 - Chinese hamster ovary cells; A549 - human alveolar epithelial cells; GD25 - murine differentiated stem cells with Itgb1 knockout (GD25-/-) and reconstitution (GD25B1A) (Fassler et al., 1995); NSO - murine myeloma, used to produce recombinant antibodies; $293 \mathrm{~F}$ - suspension-adapted human embryonic kidney cells. J774, L929, CHO-K1, A549 and GD25 cells were grown at $37^{\circ} \mathrm{C}$ and $5-10 \% \mathrm{CO}_{2}$ and maintained in Dulbecco's Modified Eagle's Media (DME) supplemented with $10 \%$ fetal bovine serum (from North American or South American origin) that was heat-inactivated by treatment at $56^{\circ} \mathrm{C}$ for $30 \mathrm{~min}, 10 \%$ Gibco NCTC-109 Media (Invitrogen), 1\% non-essential amino acids (Mediatech or Gibco) and 1\% 
Penicillin Streptomycin Solution (Mediatech or Gibco). NSO cells were maintained in the same

supplemented DME medium and were grown in CD Hybridoma chemically defined medium (Invitrogen)

in a $37^{\circ} \mathrm{C}$ incubator with $125 \mathrm{rpm}$ shaking and $5 \% \mathrm{CO}_{2} .293 \mathrm{~F}$ cells were also grown in suspension of

Freestyle $293 \mathrm{~F}$ medium (Invitrogen) also at $37^{\circ} \mathrm{C}, 5 \% \mathrm{CO}_{2}$ and $125 \mathrm{rpm}$ shaking. Adherent cells were

grown on tissue culture treated plates (BD Falcon) and removed by treatment with 3-5 $\mathrm{mL}$ Cellstripper

(Mediatech), a non-enzymatic solution for removing adherent cells, or $5 \mathrm{~mL}$ trypsin (Gibco) then pelleted by centrifugation at $300 \times \mathrm{g}$ for $10 \mathrm{~min}$, and finally re-suspended at the appropriate concentration in DME.

\section{Primary cell cultures}

Bone marrow-derived macrophages (BMMs) were differentiated from the marrow of femoral and tibial bones of donor mice. Briefly, cells were obtained by flushing the marrow and then growing in differentiation media for $6 \mathrm{~d}$ (DME media with 20\% conditioned medium from a confluent culture of L929 fibroblasts as a source of M-CSF, 10\% FCS, 10 mM Hepes, 2.0 mM L-glutamine, 0.05 mM 2mercaptoethanol, $1 \%$ nonessential amino acids, $1 \%$ penicillin and $100 \mu \mathrm{g} / \mathrm{ml}$ streptomycin). Nonadherent cells were removed and adherent macrophages recovered from plates using Cellstripper. These BMMs were then maintained in DME media with $10 \%$ L929 conditioned medium, 10\% FCS, $10 \mathrm{mM}$ Hepes, $2.0 \mathrm{mM}$ L-glutamine, $0.05 \mathrm{mM}$ 2-mercaptoethanol, 1\% nonessential amino acids, 1\% penicillin and $100 \mu \mathrm{g} / \mathrm{ml}$ streptomycin, and used within 3 days.

\section{Method details}

\section{Generation of genetically modified cell lines}

We initially amplified murine Itgb1 and Itga4 from J774 total RNA by RT-PCR. To generate Itgb1+ CHO cells, the Itgb1 insert was cloned on a pEGFP-C1 vector (Clontech, Mountain View, CA) that was transfected into $\mathrm{CHO}$ cells using Lipofectamine 2000 (Invitrogen, Carlsbad, CA). Stable transfectants 
were selected with $1 \mathrm{mg} / \mathrm{mL} \mathrm{G} 418$ and a population with high murine Itgb1 expression was selected by two consecutive rounds of flow cytometry sorting using PE-labeled HM $\beta$ 1-1. To generate GD25 cells expressing Itgb1, Itga4 or both integrins, the Itgb1 insert was cloned in the pIRES2-EGFP-blas vector (in which the NeoR resistance marker was substituted by the BlasR marker by Infusion cloning) and the Itga4 insert was cloned into the pIRES2-DsRed2 vector. Pairwise combinations of the Itgb1- and Itga4expressing plasmids as well as the empty vectors were co-transfected into GD25-/- cells using Lipofectamine 3000 (Invitrogen). All the sequences in these vectors were confirmed by Sanger sequencing before transfection.

\section{Hybridoma antibodies.}

The $C$. neoformans-specific monoclonal antibodies, 3E5 IgG1 and IgG3 have been described previously (Yuan et al., 1995). Briefly, mAb 3E5 was originally isolated as an IgG3 mAb following immunization of mice with GXM conjugated to tetanus toxoid (Mukherjee et al., 1993), and the other isotypes were later generated via in vitro isotype switching (Yuan et al., 1995). Ascites was generated by injecting hybridoma cells into the peritoneal cavity of pristane-primed BALB/c mice (National Cancer Institute, Frederick, MD) and harvesting the fluid. Abs were purified from ascites using a protein $\mathrm{G}$ column following the manufacturer's instructions (Pierce, Rockford, IL), then dialyzed in PBS and quantified by ELISA with an isotype-matched standard to determine concentration. For quantification, ELISA plates were coated with serial dilutions of purified myeloma $\lg G 1 / k$ (MOPC 21) and IgG3/k (FLOPC 21) standards (Cappel) and dilutions of the purified antibodies. After blocking with bovine serum albumin (BSA), bound antibodies were detected with alkaline phosphatase-conjugated isotype-specific goat antimouse polyclonal serum (Southern Biotech). 


\section{Recombinant antibodies}

\section{Synthetic genes and cloning}

To produce $2 \mathrm{H} 1$ and 4-4-20 mlgG1/mlgG3 recombinant antibodies, the heavy (VH) and light chain (VL) variable regions of $2 \mathrm{H} 1$ (Young et al., 1997) and 4-4-20 (Whitlow et al., 1995) antibodies were codonoptimized and synthetized by GenScript and then cloned into the commercially available pFUSE vectors, the VHs into the pFUSEss-CHIg-mG1 and pFUSEss-CHIg-mG3 vectors and the VLs into the pFUSEs-CLIgmk (InVivoGen). All constructions were confirmed by Sanger sequencing before transfection. NSO cells were seeded at $8 \times 10^{5}$ cells $/ \mathrm{mL}$ in 24 -well plates 24 hours before transfection and then co-transfected with the pFUSEss-CHIg-mG1 or pFUSEss-CHIg-mG3 and the pFUSEs-CLIg-mk vectors containing the VH and VL sequences for $2 \mathrm{H} 1$ or 4-4-20 antibody expression. Transfections were made using Lipofectamine2000 (Invitrogen), following manufacturer instructions. 72 hours post-transfection cells were set to selection by addition of Zeocin (Invitrogen) at $1 \mathrm{mg} / \mathrm{mL}$ and Blasticidin (Gibco) at $5 \mu \mathrm{g} / \mathrm{ml}$. After three weeks of selection stable antibody producing cells were obtained. These cells were adapted to serum free medium, CD Hybridoma AGT (TermoFisher), supplemented with $1 x$ cholesterol (Gibco) and $8 \mathrm{mM} \mathrm{L-Glutamine} \mathrm{(Sigma} \mathrm{Aldrich).} \mathrm{The} \mathrm{culture} \mathrm{volume} \mathrm{was} \mathrm{then} \mathrm{escalated} \mathrm{to} 1 \mathrm{~L}$ to produce the first lots of $2 \mathrm{H} 1$ and 4-4-20 mlgG1 /mlgG3 recombinant antibodies. Subsequent lots of the recombinant antibodies were produced by thawing and expansion of frozen antibody producing cells adapted to serum free medium, obtained as described above. Recombinant antibodies were purified by either, anionic exchange chromatography using a HiScreen DEAE FF column (GEHealthcare) in a non-binding mode, followed by a two-step ammonium sulphate precipitation at $64 \%$ saturation, size exclusion chromatography with PBS buffer using a HiLoad 16/600 Superdex 75 pg column (GEHealthcare), or by affinity chromatography using Protein G GraviTrap columns (GEHealthcare), following instructions on manual, and then concentrated by ultrafiltration. Quantification was made by direct ELISA as described above for hybridoma antibodies or by an antigen-specific ELISA for preparations with low concentration. 
For the antigen-specific ELISA, plates were coated with $10 \mu \mathrm{g} / \mathrm{mL}$ of GXM purified from C. neoformans H99 cultures. After blocking with bovine serum albumin (BSA), serial dilutions of isotype specific antibodies IgG1 (18B7) or IgG3 (3E5) and purified recombinant antibodies were added to wells and detected with alkaline phosphatase-conjugated isotype-specific goat anti-mouse polyclonal serum (Southern Biotech). 2H1 antibodies were validated by indirect immunofluorescence with $\mathrm{C}$. neoformans cells (Figure S4).

\section{C. neofomans phagocytosis assay}

Phagocytosis assays were performed in 96 well tissue-culture treated plates (BD Falcon) containing either primary peritoneal cells isolated one day prior to the experiment, BMM cultured to maturity, or $\mathrm{J} 774$ cells plated at least $2 \mathrm{~h}$ or up to one day before the experiment. In some experiments, various receptors were blocked using receptor-specific Abs prior to phagocytosis. For CR block, a cocktail containing Abs to $C R 3$ and $C R 4$ (CD18, CD11b, and CD11c; BD Pharmingen) are known to be effective at blocking CR function (Taborda and Casadevall, 2002). For FcyRII and FcyRIII block, the 2.4G2 Ab (BD Pharmingen) was used. For FcyRI block, monomeric IgG2a was used as a competitive inhibitor. For Itgb1 block, the unlabeled mAb HMß1-1 was used, which has been shown to be effective at binding and inhibiting adhesion of tumor cell lines to extracellular matrix via Itgb1 (Noto et al., 1995). Blocking Abs were added at concentrations ranging from 10 to $50 \mu \mathrm{g} / \mathrm{mL} 30$ minutes before addition of the fungi and opsonizing antibody. Then, the C. neoformans suspension with opsonizing Ab (IgG1, IgG3 or 18B7, as indicated) was added, with blocking Abs at $10 \mu \mathrm{g} / \mathrm{mL}$, opsonizing Abs at $10 \mu \mathrm{g} / \mathrm{mL}$, and the macrophage to $C$. neoformans ratio ranging from $1: 1$ to $1: 2$. Phagocytosis was allowed to proceed for $2 \mathrm{~h}$, at $37^{\circ} \mathrm{C}$ in $5-10 \% \mathrm{CO}_{2}$. Cells were then washed, fixed with methanol at $-20^{\circ} \mathrm{C}$ for 30 minutes and finally stained with Giemsa. Cells were then analyzed under an inverted microscope, counting three fields/well, with at least 100 cells/field. Macrophages with internalized $C$. neoformans were readily distinguishable from cells that had taken up no fungi, or from those in which C. neoformans was simply attached to the outside, 
due to the visible vacuole containing engulfed cell. Percent phagocytosis is calculated as the number of macrophages containing one or more internalized $C$. neoformans divided by the total number of macrophages visible in one field. At least one hundred macrophages were counted in each condition.

Phagocytosis assays to determine alpha integrin partner were performed using an automated microscopy platform, as described previously (Coelho et al., 2012). Briefly, macrophages were seeded in a glass-bottom 96-well plate (MGB096-1-2-HG-L; Matrical Biosciences, Spokane, WA) at a density of $2.4 \times 10^{4}$ cells/well and phagocytosis of $C$. neoformans proceeded as described above. After a $2 \mathrm{~h}$ period to allow phagocytosis, cells were fixed with methanol and stained consecutively with wheat germ agglutinin conjugated to Alexa Fluor 633 (Invitrogen) for detection of macrophage cytoplasmic membrane, Uvitex 2B (Polysciences, Inc., Warrington, PA) at a $0.1 \mathrm{~g} / \mathrm{mL}$ to stain $C$. neoformans cells and finally propidium iodide (Sigma) at $5 \mu \mathrm{g} / \mathrm{mL}$. Images were acquired and analyzed in iCys Compucyte (CompuCyte Corp., Westwood, MA) with a 40x objective with at least 15 images per field averaging around 700 cells per well in triplicate wells.

\section{Pooled shRNA library transduction and sorting}

A pool of lentiviral vectors containing approximately 80,000 different shRNA sequences targeting about 15,000 different mouse genes was obtained from Sigma-Aldrich, the distributor for the product developed by the RNAi Consortium (Luo et al., 2008; Root et al., 2006). J774 cells were maintained as indicated above and were plated in $10 \mathrm{~cm}$ tissue cultured treated plates (BD Falcon) one day prior to transduction to generate 10 plates the next day, each at a density of $2 \times 10^{6} \mathrm{~J} 774$ cells per plate. Hexadimethrine bromide (Sigma) was added at $8 \mu \mathrm{g} / \mathrm{mL}$ to facilitate transduction, and $2 \times 10^{5}$ viruses were added to each plate of $\mathbf{J 7 7 4}$ cells to maintain a multiplicity of infection of 0.1 . Cells were incubated with virus $24 \mathrm{~h}$, the media was then changed and the cells were incubated an additional day. At this point, $5 \mu \mathrm{g} / \mathrm{mL}$ of Puromycin (Sigma) was added and cells were grown under selection for $2 \mathrm{~d}$. After selection, dead cells were removed and cells were replated under continued puromycin selection, and 
allowed to recover overnight. Next day the $4.6 \times 10^{7}$ total cells were stained with two labeled Abs: mlgG3-DTAF and mIgG1-APC. The mlgG3 was the 3E5 mAb featured in other experiments, generated as indicated in the previous section, and labeled with dichlorotriazinylaminofluorescein (DTAF, Sigma) according to the protocol for labeling amine-reactive probes following provided instructions (Invitrogen). Mouse IgG1 isotype control Ab conjugated to APC was purchased (Southern Biotech). For the sorting of transduced cells: staining was carried out in Cellstripper for $1 \mathrm{~h}$ at $4^{\circ} \mathrm{C}$. Afterwards, the cells were collected by centrifugation, washed twice, and then filtered in a $40 \mu \mathrm{m}$ cell strainer and analyzed on the MoFlo XDP Sorter (Albert Einstein College of Medicine Flow Cytometry Core Facility). Sorting gates were generated for cells with high lgG1 signal and low IgG3 signal, and this first sort was run in "yield" mode to get the highest return. We recovered $1.5 \times 10^{6}$ cells that were then grown under continued puromycin selection for one week, after which we performed a second sort under similar conditions as above except in "purity" mode to increase the selectivity of the method and recover only those cells in the sorting gate population. We recovered approximately 50,000 cells in the post-sort population and maintained them in culture under puromycin selection. A portion of $\mathrm{J774}$ cells not subjected to sorting was also maintained as the pre-sort population. These cell populations were maintained under puromycin selection and used for DNA extraction and sequencing. Following bioinformatics analysis, 17 specific shRNA lentiviral vectors were purchased, corresponding to our candidate selection criteria. These individual shRNAs were transduced into $\mathrm{J774}$ cells following a similar protocol, maintained as separate transduced cell lines, and analyzed as indicated.

\section{Flow cytometry and sorting}

To analyze the binding of either IgG1 or IgG3 mAbs, or to analyze expression of Itgb1, transduced $J 774$ cells were maintained as indicated above and prepared for flow cytometry. Approximately $1 \times 10^{6}$ cells were harvested and suspended in $1 \mathrm{ml}$ Cellstripper solution to prevent attachment, and $10 \mu \mathrm{l} \lg \mathrm{g} 1-$ Alexa568 and IgG3-Alexa488 were added. These Abs were made by conjugating the 3E5 IgG1 and IgG3 
mAbs with their respective Alexa fluorophore following the kit instructions (Molecular Probes, Eugene, OR). For staining Integrin beta 1 (Itgb1), phycoerithrin-labeled HMß1-1 was used at 1:100 dilution. After staining for $1 \mathrm{~h}$ at $4^{\circ} \mathrm{C}$, cells were centrifuged and washed twice, then analyzed on BD LSR II or BD FACS Aria at the Albert Einstein College of Medicine Flow Cytometry Core Facility. Flow cytometry data were analyzed with Flow-Jo (Treestar, Inc.) and presented as the median fluorescence intensity, histograms or density plots. For the case of Itgb1 sorting, J774 cells transduced with the 5 individual shRNAs targeting Itgb1 were analyzed for surface expression, and the group of cells with lowest Itgb1 staining were sorted and maintained.

\section{DNA extraction and sequencing}

Genomic DNA was extracted from the pre- and post-sorted $\mathrm{J774}$ cells populations using a commercial kit (QIAGEN, Valencia, CA). Primers flanking the shRNA region were used to amplify the shRNA sequences from $1.5 \mu \mathrm{g}$ of DNA. The amplified library was then analyzed with a Solexa sequencer (Illumina, Inc., San Diego, CA). Partners Healthcare (Cambridge, MA) performed PCR amplification and high-throughput sequencing on pre- and post-sort DNA samples. Seqwise LLC (Boston, MA) performed bioinformatics on the sequencing data to generate actual counts.

\section{Quantification and statistical analysis}

Bioinformatics data from the shRNA high-throughput sequencing was analyzed with the Audic and Claverie method for pairwise testing (Audic and Claverie, 1997; Romualdi et al., 2003). Phagocytosis assays were analyzed on Graphpad Prism 7.0; pairwise comparisons were made with the Fisher's exact test to compare the proportions of macrophages which internalized $C$. neoformans cells. Confidence intervals for the proportions were calculated using the Wilson/Brown method. 
